\title{
Effect of Eugenol and Non-eugenol Containing Temporary Cement on Permanent Cement Retention and Microhardness of Cured Composite Resin
}

\author{
Funda BAYINDIR, M. Şamil AKYIL and Yusuf Ziya BAYINDIR ${ }^{1}$ \\ Prosthodontics Department, \\ ${ }^{1}$ Conservative Dentistry Department, School of Dentistry, \\ Ataturk University, Erzurum, Turkey
}

Received March 31, 2003/Accepted June 26, 2003

\begin{abstract}
This present study had three aims: 1) to evaluate the bond strengths of carboxylate and resin cements in cementing cast $\mathrm{Co}-\mathrm{Cr}$ crowns to pretreatment of composite resin cores with eugenol and non-eugenol containing temporary cements, 2) to determine the microhardness of composite resin treated with temporary cement, 3) to view the surface differences of composite resin with SEM.

The composite cores were divided into three experimental groups for the following pretreatments: Group 1, No treatment was provided, Group 2, The external walls of the composite cores were covered with eugenol-containing temporary cement, Group 3, The external walls of the composite cores were covered with non-eugenol containing temporary cement.

Analysis of variance results showed that there was a significant difference between all three groups. Temporary cement with eugenol was significantly reduced the bond strength of full crown casting with resin cement compared with non-eugenol.

The resin specimens treated with the eugenol-containing temporary cement showed the lowest microhardness values, the non-eugenol-containing temporary cement was not significantly different from those of the control groups.
\end{abstract}

Key words: Temporary cements, Composite resin, Bond strength

\section{INTRODUCTION}

Composite resins are commonly used for cores for both vital and nonvital teeth. Their properties allow the completion of a core in one visit. Compared with other restorative methods, this means a reduction in chair time and hence a substantial saving to the dentist and patient ${ }^{1)}$.

Provisional and permanent crowns and fixed partial dentures are commonly cemented with eugenol-containing temporary cements ${ }^{2)}$. Eugenol is known to be incompatible with resin polymers. It has been shown that eugenol-containing bases and liners partially inhibit the polymerization of freshly mixed composite resin restorations and that there is a softening of the resin surface adjacent to the eugenol lin$\mathrm{ers}^{3-5)}$. This phenomena raises the question of whether cured composite resins are immune to effects of eugenol such a question is relevant since an adverse effect by eugenol may require different handling of temporary crowns over composites resin cores $^{6)}$. Application of eugenol-containing cement to cured composite resin cores before final cementation with resin cement significantly reduced retention of the 
crowns $^{7)}$. The compatibility of different dental materials root canal sealer and composite core build-up restorative is an important factor for a successful restoration ${ }^{8)}$.

This study had three aims; 1 ) to evaluate the bond strengths of carboxylate and resin cements in cementing cast $\mathrm{Co}-\mathrm{Cr}$ crowns to pretreatment of composite resin cores with eugenol and non-eugenol containing temporary cements, 2) to determine the microhardness of composite resin treated with eugenol and a non-eugenol containing temporary cement, 3) to examine the surface differences of composite resin with SEM.

\section{MATERIALS AND METHODS}

\section{Bond strength}

Maxillary first premolar teeth prepared as a core form and this sample used as a master model. Using this master model a mould prepared with elastomeric impression material (Speedex putty and light body, Coltene, Altsötten, Sweden). The mould filled with Dynamic universal composite resin (President, Dynamic Universal Hybrit Composite, Munich, Germany) to produce the cores and total 60 core forms were made. Co-Cr (Wironit, Bego, Bremen, Germany, Co: 64.0, Cr: 28.65, Mo: 5.0, C: $\max$. 0.35, Si, Mn: 0.5) full crown casting made to fit a standard maxillary first premolar crown preparation were prepared. A simple wax pattern with a loop attached to the occlusal surface of crowns. The cast samples produces by the lost-wax technique in a centrifugal, induction-heated casting machine (Rotaks Dent. Diş Tic. AŞ. Beyoğlu/ Istanbul) according to the manufacturer's instructions.

Before cementation the composite cores were divided into three experimental groups for the following pretreatments,

Group 1, No treatment was provided (control group)

Group 2, The external walls of the composite resin cores were covered with eugenol-containing temporary cement (Temp-Bond, Kerr Co., Salerno, Italia)

Group 3, The external walls of the composite cores were covered with noneugenol containing temporary cement (Provilat (eugenol-free), Promedica, Neumunster, Germany).

Temporary cement prepared at an ambient temperature of $18^{\circ} \mathrm{C}$ to $23^{\circ} \mathrm{C}$ and relative humidity of 45 to $55 \%$. Two equal lengths of paste and catalyst were mixed using a metal spatula to thoroughly mix the paste for $30 \mathrm{sec}$ until a homogenous consistency was achieved. After application of the temporary cement the composite cores were stored in distilled water at $37^{\circ} \mathrm{C}$ and $100 \%$ humidity for 10 days. After the 10 days, the specimens removed this environment. The temporary cements were mechanically removed using a hand instrument. Then 30 specimens were cemented with carboxylate cement (Durelon Espe, 3M ESPE AG, Seefeld, Germany); another 30 specimens were cemented with resin cement (Duo-cement kit, Coltene, Altsötten, Sweden). Equal amounts of base and catalyst paste were mixed following the manufacturer's instructions and applied to the core and the samples were held together with firm finger pressure for 5 min until setting was complete. This procedure was 


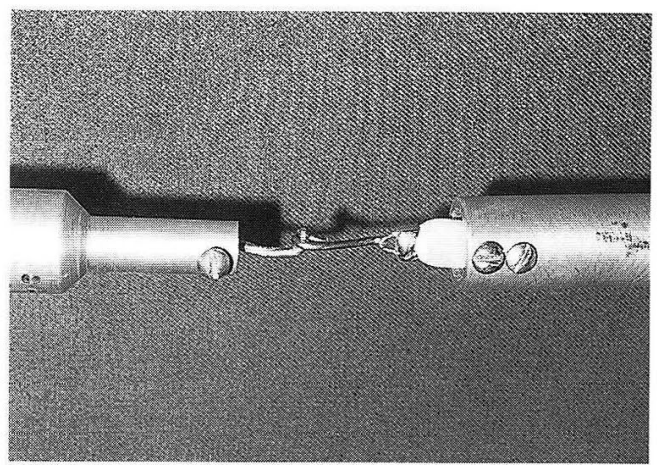

Fig. 1 Separation force applied for test specimens.

repeated for carboxylate cement.

These samples were stored in distilled water at $37^{\circ} \mathrm{C}$ and $100 \%$ humidity for 10 days. After storage the bond strength was measured using a press and pull machine (Haunsfield Test equipment company, Croydon, England) in tensile mode at a crosshead speed of $5 \mathrm{~mm} / \mathrm{min}$ (Fig. 1).

\section{Evaluation of microhardness}

Thirty fiberglass moulds (internal diameter $5 \mathrm{~mm}$, height $2 \mathrm{~mm}$ ) were made and placed on a flat glass plate. Moulds were filled with resin composite light cure, according to the manufacturer's directions for use. Each specimen was polymerized for 60 sec. (Translux EC, Kulzer, Wehrheim, Germany). After setting, the specimens were removed from the mould and randomly divided into three experimental groups $(\mathrm{n}=10)$.

After application of the cements the resin composite specimens and control group were stored at $37^{\circ} \mathrm{C}$ and $100 \%$ humidity for 10 days. The specimens were removed from this environment. The temporary cements were removed mechanically using a hand instrument.

The Vickers surface hardness was measured with a microhardness tester (Micromet 1600-4980T, Buehler GmbH, Dusseldorf, Germany). A diamond pyramid surface indenter was used with a load of $25 \mathrm{~kg}$ for 15 -sec. The Vickers hardness was obtained using the following formula.

$$
\mathrm{VH}=1.854 \mathrm{P} / \mathrm{d}^{2}
$$

( $\mathrm{P}=$ applied load in $\mathrm{kg}, \mathrm{d}=$ average length of the measured diagonals in $\mathrm{mm}$ ). Three measurements were made on each specimen and the mean was recorded for the three readings.

Following data collection, the SPSS $(10: 0)$ statistical software program was used for statistical evaluation. The mean values, standard deviations of the bond strength and microhardness were calculated. The results were compared statistically 
using the one-way analysis of variance test. Duncan's post hoc test was used to determine the group mean differences, when significant differences were noted.

\section{Evaluation of SEM}

After the microhardness evaluation, all surfaces were coated with palladium-gold and viewed using a scanning electron microscope (SEM)(JSM 6400, JEOL, Tokyo, Japan).

\section{RESULTS}

Mean bond strengths were calculated (Table 1). The results were compared statistically using an analysis of variance to compare the two luting cements and three pretreatment groups. Significant differences $(p<0.001)$ were found among the groups. This was followed by Duncan's post hoc test, when a significant difference was noted in the analysis of variance (Table 2). The resin cores pretreated with eugenol-containing temporary cement and cemented with resin cement clearly had lower bond strength values than the other groups $(16.0 \mathrm{~N})$. In the control group, the resin cements produced the highest bond strength value $(200.0 \mathrm{~N})$. Between the carboxylate cements in the control group $(46.0 \mathrm{~N})$ and pretreatment non-eugenol groups $(58.0 \mathrm{~N})$ no significant difference was found.

Table 3 presents the Vickers microhardness values for the three groups. The

Table 1 The means and standard deviations of bond strength values

\begin{tabular}{l|rrrr}
\hline \multicolumn{1}{c|}{ Group } & $\begin{array}{r}\text { Mean } \\
(\mathrm{N})\end{array}$ & \multicolumn{1}{c}{$\begin{array}{c}\text { Std. } \\
\text { Dev. }\end{array}$} & min. & max. \\
\hline Resin cement \& eugenol containing temporary cements & 16.0 & 5.16 & 10.0 & 20.0 \\
Resin cement \& non-eugenol containing temporary cements & 67.0 & 10.59 & 50.0 & 80.0 \\
Resin cement; Control & 200.0 & 66.50 & 130.0 & 310.0 \\
Polycarboxylate cement \& eugenol containing temporary cements & 28.0 & 12.29 & 20.0 & 50.0 \\
Polycarboxylate cement \& non-eugenol containing temporary cements & 58.0 & 10.32 & 50.0 & 70.0 \\
Polycarboxylate cement; Control & 46.0 & 17.12 & 30.0 & 90.0 \\
\hline
\end{tabular}

Table 2 Duncan's test results for the resin cement and carboxylate cement bond strengths

\begin{tabular}{l|cccccccc}
\hline \multicolumn{1}{c|}{ Resin cement } & $\mathrm{N}$ & 1 & 2 & 3 & $\begin{array}{c}\text { Carboxylate } \\
\text { cements }\end{array}$ & $\mathrm{N}$ & 1 & 2 \\
\hline Temp-Bond (eugenol) & 10 & 16.0 & & & & 10 & 28.0 & \\
$\begin{array}{l}\text { Provilat (non-eugenol) } \\
\text { Control }\end{array}$ & 10 & & 67.0 & & & 10 & & 58.0 \\
Sig. & 10 & & & 200.0 & & 10 & & 46.0 \\
\hline
\end{tabular}

$\alpha: 0.05$

Table 3 Vickers surface microhardness values for the test groups

\begin{tabular}{l|ccccc}
\hline \multicolumn{1}{c|}{ Group } & $\mathrm{N}$ & min. & max. & Mean & Std. Dev. \\
\hline Temp-Bond (eugenol) & 10 & 13.24 & 23.76 & 17.58 & 3.28 \\
Provilat (non-eugenol) & 10 & 20.26 & 30.15 & 27.43 & 3.30 \\
Control & 10 & 18.54 & 44.80 & 32.49 & 8.66 \\
\hline
\end{tabular}


Table 4 Duncan's test results for the microhardness value

\begin{tabular}{l|ccc}
\hline \multicolumn{1}{c|}{ Group } & $\mathrm{N}$ & 1 & 2 \\
\hline Temp-Bond (eugenol) & 10 & 17.58 & \\
Provilat (non-eugenol) & 10 & & 27.43 \\
Control & 10 & & 32.49 \\
Sig. & & 1.000 & 0.056 \\
\hline
\end{tabular}

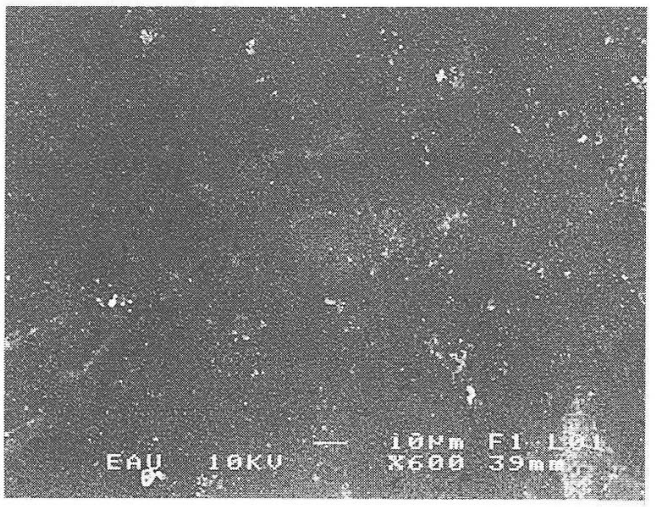

Fig. 2 Scanning electron micrograph of the control group.

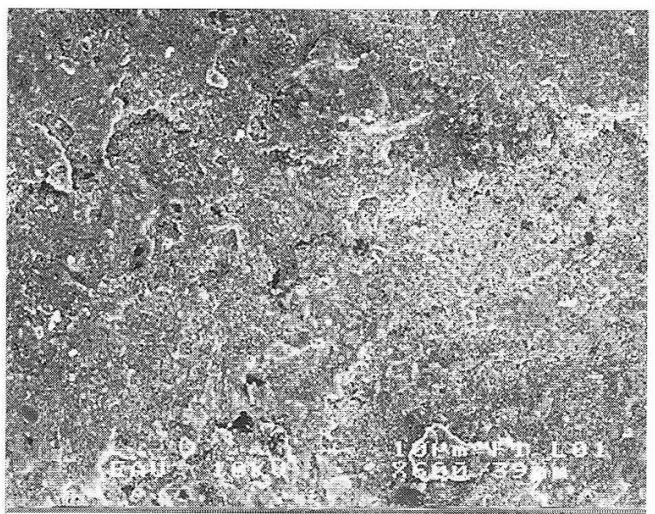

Fig. 3 Scanning electron micrograph of composite resin sample pretreated with eugenol containing cement.

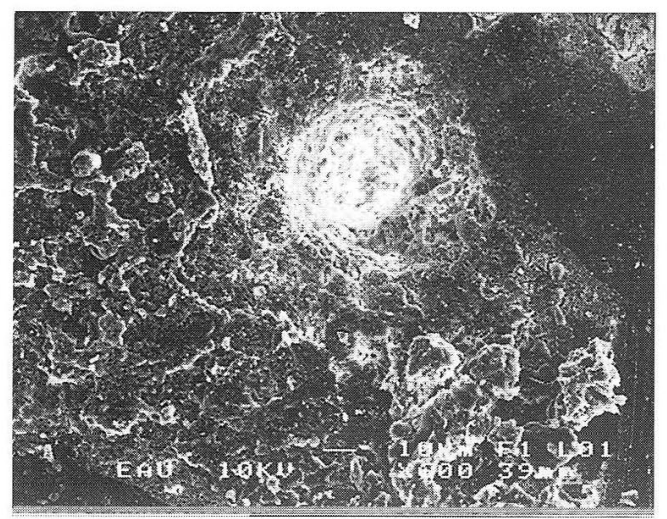

Fig. 4 Scanning electron micrograph of composite resin sample pretreated with non-eugenol containing cement.

highest microhardness values were observed for the control group. According to the analysis of variance results, there was a significant difference among the three groups $(\mathrm{p}<0.001)$. Resin specimens treated with the eugenol-containing temporary cement showed the lowest microhardness value than the other groups. Table 4 showed Duncan's post hoc test.

Figs. 2 to 4 show SEM photomicrographs of the composite resin samples. The 
control group showed a smooth surface compared with the other sample micrographs (Fig. 2). The eugenol treated sample is shown in Fig. 3. The surface displays an abraded appearance noticeably different from the control group surface. In the noneugenol group, the filler particles were less visible and the porosities in the resin were filled with temporary cement (Fig. 4).

\section{DISCUSSION}

Eugenol is a phenol derivative used in combination with zinc oxide as pulp capping agents, temporary cement and root canal filling cement. Eugenol reacts with free radicals, thereby inhibiting the polymerization of methacrylate monomers. Thus, it is incompatible with the resin restorative system $^{3)}$.

Benzoyl peroxide (BPO) is widely used as an indicator of the resin system in dentistry. BPO induces decomposition in the initiation of polymerization of methacrylate and its free radicals kinetics first and second order processes ${ }^{9}$. BPO decomposes very rapidly in the presence of phenol derivates, when they were investigated as solvents for $\mathrm{BPO}$ decomposition at $60-80^{\circ} \mathrm{C}^{10)}$. Phenol derivates such as eugenol are chain-breaking and radical destroyers ${ }^{11}$.

Fujisawa and Kadoma ${ }^{12)}$ suggested that eugenol acts as a retarder against the polymerization of the resin system, when excess eugenol interacts with BPO and its related compounds.

Composite resins were studied both as material for the post-core itself and for the cementing agents ${ }^{7,13,14}$ Many studies reported on the bonding properties of eugenol cements with resin composite ${ }^{7,13,15-20)}$. Yap et $a .^{21)}$ demonstrated that eugenolcontaining temporary cements had significantly lower bond strengths of composite to dentine. The present research showed that resin cement exhibits stronger bond strengths to composite resin cores than does carboxylate cement in the control group. The resin cores pretreated with eugenol-containing temporary cement and cemented with resin cement showed the lower bond strength values than the noneugenol-containing temporary cement group.

Millstein and Nathanson ${ }^{6 /}$ reported that eugenol and eugenol-containing cements can alter the surface of cured composite resin. They also stated that this might be due to the combined effects of eugenol, the adhesive properties of temporary cements, and the rubbing action required to remove the cement. The incomplete removal of temporary cement from a cured composite resin core may affect the quality of cementation of the final restoration.

Millstein and Nathanson ${ }^{7)}$ also compared the effects on retention of base metal cylindrical retainers placed on composite resin cores when pretreated with eugenol and non-eugenol temporary cements. They showed that the application of eugenolcontaining cement to cured composite resin cores before final cementation with resin cement significantly reduced retention of the crowns. Cohen et al. ${ }^{8)}$ stated that if the eugenol directly contacts before curing the composite resin, they do not achieve a full cure or hardness. In the present study evaluated the effect of contact with eugenol 
containing cement on cured composite resin was evaluated.

The combinations of resin core and resin cement produced bond strength values two to three fold greater than bond strength produced by polycarboxylate cement. It is possible that a chemical bond occurred between the resins cement and the resin core, enhancing bond strength ${ }^{7)}$.

Various studies investigated changes in the bond strengths and surface hardness of resin composites in different storage media ${ }^{15,16,22,23)}$. Gregory and Campbell ${ }^{24)}$ stated that the surface hardness of current conventional and hybrid composite resin was adversely affected by exposure to temporary luting agents compared with controls. The temporary cements invariably failed at the interim acrylic crown interface while the zinc phosphate cement failed at the core interface. The use of $\mathrm{Ca}(\mathrm{OH})_{2}$, as an temporary luting agent for acrylic crowns over hybrid cores compared with eugenol or non-eugenol containing temporary cements, should afford significantly greater bond strength with no adverse effect on the bond strength of the final casting.

SEM micrograph showed that eugenol containing temporary cement can alter the surface of cured composite resin. Mechanical abrasion and softened rough surfaces were observed. Control group exhibited smoother surface. The treated surface was significantly rougher than the control group. The findings of present study showed that eugenol containing temporary cement affected the surface hardness of a resin composite. The surface hardness of resin composite was significantly reduced by eugenol-containing cement. A softening was observed in the eugenol containing cement and this result was significantly different compared with the non-eugenol containing cement groups.

\section{CONCLUSIONS}

One limitation of this study was that bond strength was greatly reduced when composite core samples were pretreated with eugenol-containing temporary cement. In control groups the resin cements produced the highest bond strength value. In this study, it was suggested that eugenol-containing cements can alter the surface of cured composite resin, and this alteration affects the success of the final restoration.

The results of the present study showed that the eugenol containing temporary cements affected the surface hardness of composite resin. The resin surface was softened by eugenol containing temporary cement. The resin specimens pretreated with the eugenol containing temporary cement showed the lowest microhardness values. Although the porous surface of treated surfaces varied from sample to sample, all control surfaces appeared to be smooth and unaffected in SEMs.

\section{REFERENCES}

1) Baraban, D. J.: Immediate restoration of pulpless teeth, J Prosthet Dent 28:607, 1972.

2) Dinckal, N.: Cements, Atatürk Üniv. DişHek. Fak. Derg. 3(2): 57-62, 1993.

3) Phillips, R.W.: Skinner's science of dental materials. 8th ed, W. B. Saunders, Philadelphia: 1982 pp 489. 
4) Grajower, R., Hirschfeld, Z. and Zalkind, M.: Compatibility of a composite resin with pulp insulatiny materials. A scanning electron microscope study, $J$ Prosthet Dent 32 : 7077, 1974.

5) Grajower, R., Hirschfeld, Z. and Zalkind, M.: Observations on cavity liners for composite resin restorations, $J$ Prosthet Dent 36 : 265-273, 1976.

6) Millstein, P. L. and Nathanson, D.: Effect of eugenol and eugenol cements on cured composite resin, $J$ Prosthet Dent 50 : 211-215, 1983.

7) Millstein, P. L. and Nathanson, D.: Effect of temporary cement on permanent cement retention to composite resin cores, J Prosthet Dent 67 : 856-859, 1992.

8) Cohen, B. I., Volovich, Y., Musikant, B. L. and Deuthsch, A. S.: The effects of eugenol and epoxy-resin on the strength of a hybrid composite resin, $J$ Endod 28(2) : 19-82, 2002.

9) Turner R. C.: Free radical decay kinetics in PMMA bone cement, $J$ Biomed Mater Res $18: 467-473,1984$.

10) Nozaki, K. and Bartlett, P. D.: The kinetics of decomposition of benzoyl peroxide in solvent(1), J Am Chem Soc 68 : 1686-1692, 1946.

11) Burton, G. W. and Ingold, K. U.: Autoxidation of biological molecules. The antioxidant activity of vitamin $\mathrm{E}$ and related chain-breaking phenolic antioxidants invitro, $J A m$ Chem Soc 103 : 6472-6477, 1981.

12) Fujisawa, S. and Kadoma, Y.: Action of eugenol as a retarder against polymerization of methyl methacrylate by benzoyl peroxide, Biomaterials 18:701-703, 1997.

13) Combe, E. C., Shagblouf, M. S., Walts, D. C. and Wilson, N. H. F.: Mechanical properties of direct core build-up materials, Dental Mater 15 : 158-165, 1999.

14) Yeşil Z.: The study of cast crowns strength of retention to the "core" materials, Atatürk Üniv. Diş Hek. Fak. Derg. $7: 53-56,1997$.

15) Jung, M., Granss, C. and Senger, S.: Effect of eugenol-containing temporary cement on bond strength of composite to enamel, Oper Dent 23(2) :63-68, 1998.

16) Granss, C. and Jung, M.: Effect of eugenol-containing temporary cements on bond strength of composite to dentin, Oper Dent 23(2) : 55-62, 1998.

17) Wazzen, K. A., Herbi, A. A. and Harmand, I. A.: The effect of eugenol-containing temporary cements on bond strength of two resin composite core materials to dentin, $J$ Prosthodont 6(1) : 37-42, 1997.

18) Terata, R., Nakashima, K., Obara, M. and Kuboto, M.: Characterization of enamel and dentin surfaces after removal of temporary cement effect of temporary cement on tensile bond strength of resin luting cement, Dent Mater $J$ 13(2) : 148-154, 1994.

19) Shwartz, R., Davis, R. D. and Mayhew, R.: Effect of ZOE temporary cement on the bond strength of a resin luting cement, Am J Dent 3(1):28-30, 1990.

20) Woody, T. I. and Davis, R. D.: Effect of eugenol-containing and eugenol free temporary cements on microleakage resin bonded restorations, Oper Dent 17(5): 175-180, 1992.

21) Yap, A. V., Shan, K. C., Lah, E. T., Sim, S. S. and Tan, C. C.: Influence of eugenol containing temporary restorations on bond strength of composite to dentin, Oper Dent 26(6) : 556-561, 2001.

22) Chadwick, R. G., McCobe, J.F., Walls, A.W. G. and Storer, R.: The effect of storage media upon the surface microhardness and abrasion resistance of three composites, Dent Mater $6: 123-128,1990$.

23) Freud, M. and Mungsgaard, E. C.: Enzymatic degradation of BISGMA/TEGDMA polimers causing decreased microhardness and greater wear in vitro, Scand $J$ Dent Res 98 : 351-355, 1990.

24) Gregory, W. A. and Campbell, Z.: Interim luting agents, composite core surface hardness and retention of interim and final restorations, Am J Dent 3(5) :207-212, 1990. 